\title{
Developing system supplier capability by integrating knowledge with customers
}

Inga-Lill Carlsson

The self-archived version of this journal article is available at Linköping University Electronic Press:

http:// urn.kb.se/ resolve?urn=urn:nbn:se:liu:diva-139588

N.B.: When citing this work, cite the original publication.

Carlsson, I., (2017), Developing system supplier capability by integrating knowledge with customers, International J ournal of Logistics Systems and Management.

Original publication available at:

Copyright: Inderscience

http://www.inderscience.com/ 


\section{Developing system supplier capability by integrating knowledge with}

\section{customers}

Inga-Lill Carlsson, Department of Management and Engineering, Linköping

University, Linköping, Sweden

Lars Bengtsson, Department of Industrial Engineering and Management, University

of Gävle, Gävle, Sweden

Corresponding author: Inga-Lill Carlsson, Säljesta Åsåkersv. 11, SE-820 40 Järvsö,

Sweden. Tel +46 (0)703 413129. E-mail: inga-lill.carlsson@aycee.se

Inga-Lill Carlsson is an industrial Ph.D. student in logistics and supply chain management at the University of Linköping, and at the University of Gävle, Sweden. She has extensive professional experience and has for many years worked as a business developer. Parallel to her studies she has been part of senior management in a group of small manufacturing companies. Her research focus is the development of suppliers and system supplier capabilities in small and medium-sized enterprises, facing increasing logistical demands.

Lars Bengtsson is Professor in Innovation Management at the University of Gävle, Sweden and Docent at The Royal Institute of Technology (KTH) in Stockholm. He currently leads research focusing on open innovation, supply chain management, human lean and rapid innovators in emerging economies. His research is presented in several books, for example on Knowledge Integration and Innovation, Alternatives to outsourcing, and Innovation or capital market logic. He has also published articles in leading innovation and operations management journals such as International Journal of Production and Operations Management, Creativity and innovation management, Production Planning and Control, International Journal of Technology Management, Journal of Purchasing and Supply Management, and Journal of Evolutionary Economics. 


\title{
Developing system supplier capability by integrating knowledge with customers
}

\begin{abstract}
As large corporations outsource parts of their manufacturing and services, many small and medium-sized enterprise (SME) suppliers are expected to deepen their capabilities and take on the role of system suppliers. The purpose of this paper is to analyse how knowledge integration with customers may help a SME develop system supplier capabilities. The study is based on a deep longitudinal case study of a SME manufacturer and focuses on continuous development capability as one of the core system supplier capabilities. The results show that knowledge integration (KI) with customers is an effective means to build system capability but that this is a stepwise process. The study identifies three levels of KI with customers: unidirectional knowledge transfer, mutual knowledge exchange and full-range knowledge integration. The analysis further indicates that each level of KI requires specific supplier capabilities.
\end{abstract}

Keywords: SME; small and medium-sized enterprise; Sweden; system supplier; supplier capabilities; supplier development; customer integration; KI; knowledge integration; knowledge exchange; knowledge transfer. 


\section{Introduction}

The development of system supplier capability has become increasingly important for many SMEs (small and medium-sized enterprises) and their customers. A background to this transition is that large corporations increasingly use external specialists and outsource different parts of their manufacturing and support services to contract manufacturers (Henrekson and Stenkula, 2006; Huin et al., 2002; Kim et al., 2007). In parallel, many customers look for a limited number of system suppliers or partners that take on a wider and more complex role in the supply chain, as well as possess expertise to complement and support the customer's manufacturing and product development processes (Gadde and Snehota, 2000; Handfield et al., 1999; Helander and Möller, 2008; Maloni and Benton, 1997; Tang, 2007).

Gaps still exist in the research into these changes from a SME supplier perspective (as has been pointed out by e.g. Cambra-Fierro and Polo-Redondo, 2008; Morrissey and Pittaway, 2006). Most research about commercial buyer-supplier relationships instead focusses on relatively larger firms and often takes the buyers' perspective (Smals and Smits, 2012). A question is thus how a SME can realise this transition towards system supplier capabilities. A system supplier is expected to take on extended areas of responsibility when larger customers want to reduce their complexity by relying on a few first-tier suppliers. Smith (2012) claims that supply chain transparency and partnering are important for efficiency. Not only operational tools for collaboration but also trust and similar goals and priorities are essential (Smith and Rupp, 2013). At the same time, the larger organisations often set up 'best practice' standards for SMEs to adopt (Barclay, 2005). This raises concerns about the effective distribution of the responsibilities and process knowledge between a SME supplier and its large customers. 
From a knowledge-based perspective on firms (Grant, 1996a), the restructuring of responsibilities along the supply chain represents a process of reorganising knowledge. This reorganisation is, however, not a question of simply transferring knowledge from the customer to the supplier but rather a more complex and collaborative process of creating and integrating knowledge (Berggren et al., 2011: Mandal, 2015; Tell et al., 2017). From this perspective a major challenge to the development of system supplier capabilities for SMEs is the question of how to integrate knowledge with customers.

Altogether, this points to a need for studies that contribute to knowledge on the development of system supplier capabilities for SMEs in general, and specifically on how knowledge integration (KI) with customers affects the transition towards system supply capability. The purpose of this paper is therefore to explain how the SME supplier development towards system supplier capabilities can benefit from KI through close customer collaboration.

\section{Theoretical framework}

\subsection{Defining system suppliers and system supplier capabilities}

There are several kinds of suppliers (cf. overview in Carlsson, 2009). In this study we focus on contract manufacturers that produce components for several different industrial customers and have no products of their own. A main distinction is made between contract manufacturers with and without system supplier capability. Capabilities is here understood to mean a combination of internal firm resources (e.g. Grant, 1991; Teece et al., 1997) and defined as "complex bundles of skills and accumulated knowledge, exercised through organizational processes that enable firms to coordinate activities and make use of their assets” (Day, 1994, p. 38). Day (1994) distinguishes among 
capabilities that relate to employee knowledge and skills, knowledge of technical systems, management systems, and values and norms.

A contract manufacturer without system supplier capability might be specialised as a component supplier, meaning a supplier who delivers a well-defined component or service, produced in one or a few process steps, often with highly automated production and a slim organisation.

In contrast, we define a system supplier as a contract manufacturer with overall responsibility for the functionality of a product or system of assembled components produced in several process steps, with the resulting responsibility to purchase materials and services. These firms need to manage a wider range of sourcing and production facilities and services, such as managing production forecasts throughout the supply chain and providing warehousing for customers (Zhang et al., 2005). An alternative role to full system supplier capability is to act as second-tier or even third- or fourth-tier supplier, competing primarily on price (Nath et al., 2005).

The two main types of contract manufacturers (system suppliers and non-system suppliers) differ in several dimensions. Beyond the fact that system suppliers have broader tasks and responsibilities, they differ when it comes to involvement in customer relationships. According to Gadde and Håkansson (2001), component suppliers are characterised by relatively simple customer relations, while system suppliers have more complex relationships and more interaction with customers. The two roles also differ when it comes to the supplier development process (Quayle, 2000). While a component supplier can specialise and concentrate its resources on automating production to handle larger volumes, the system supplier in addition needs to build capabilities to efficiently source components, modules or complete systems. 


\subsection{Knowledge integration}

This paper builds upon the knowledge-based view (KBV), where knowledge is regarded as the most important resource and organisations are understood to be a main locus for integrating knowledge (Grant, 1996a). According to this perspective, the knowledge at play is not limited to existing organisational borders, an insight that has been described as 'firms know more than they make' (Brusoni et al., 2001). This implies that the knowledge integration processes (Berggren et al., 2011) are about managing interorganisational relations and knowledge flows across organisational, knowledge and geographical boundaries (Tell et al., 2017). Eslami and Lakemond (2016) found that both one-dimensional flow of knowledge transfer and external sharing of knowledge bases may be relevant for knowledge integration. This implies, however, close and interactive collaboration among individuals for reciprocal learning, especially important where tacit knowledge is concerned. In this vein researchers have stressed the significance of the partners involved having similar and common knowledge (Grant, 1996b; Mandal, 2015). Successful integration of external knowledge requires internal and overlapping knowledge (Hillebrand and Biemans, 2004; Koufteros et al., 2010) and mutual trust in each other's expertise and reputation (Rosell et al., 2014).

KI can be seen as an important system supplier capability and has for instance been analysed by Berggren et al. (2011), who define 'knowledge integration as the bringing together and combining different types of knowledge required for developing new products, systems and solutions and generating the requisite complementary knowledge' (p. 7).

Experience, skills and knowledge that have evolved in a company over a long time are attributes that must be identified, preserved and encouraged to grow and mature in order to create KI capability to enhance performance and meet customer expectations. But a keen awareness of the need for changes is also necessary, since 
long-term investments in technology and knowledge may create detrimental path dependencies and a need to ‘unlearn’ (Sydow et al., 2009). Major areas that make up KI capability include strategic capabilities, especially leadership and management, and organisational structures that enable and promote knowledge exchange and integration (Berggren et al., 2011). Often a distinction is made between tacit and explicit knowledge (Eslami and Lakemond, 2016; Wu and Lin, 2013; Yang, 2013; Yazici, 2013). Explicit knowledge can be dealt with by contractual means, whereas tacit knowledge, on the other hand, requires trust and stability and must be managed with relational means. Yazici (2013) claims that certain contract types, such as preferred buyer-supplier contracts, emphasise relational trust and experience between the parties and thus facilitate the sharing of both explicit and tacit knowledge. Systems and procedures for managing $\mathrm{KI}$ are important, as are the people involved in these areas shaping or interacting with them.

Previous studies also show the importance to KI processes of different types of trust. Rosell et al. (2014) suggest that capturing knowledge requires basic competencebased trust; the integration of knowledge relies on more relational-based processes and trust. Similarly Yang (2013) found that explicit knowledge may be governed by contractual means, while tacit knowledge requires relational stability and trust. In particular, the sharing of tacit knowledge needs to be based on the richer context that may follow from a long-term buyer-supplier partnership (Wu and Lin, 2013).

\subsection{Previous studies on development of system supplier capabilities}

Existing research on how to build system supplier capabilities from a SME perspective is quite rare. Previous studies have, however, identified a number of demands as basic or generic, seen as equally important to all types of contract manufacturers: delivery 
precision and short lead times, quality and environmentally sustainable work, price and price-reducing activities, flexibility, and certain order-related communication and information activities (see e.g. Carlsson 2009; Hilmola et al., 2015; Kannan and Tan, 2003). Managing these basic capabilities is suggested as a necessary stepping stone for the aspirant to the system supplier role (Carlsson, 2009). Some capabilities stand out as notably different for system suppliers compared to component suppliers: capabilities of information and communications management, supply chain management, relationship management, process development and project management, and capabilities of design and construction. Most important are the management capabilities of the system supplier, because they direct the efforts to develop and maintain other capabilities (see e.g. Heide et al., 2008).

The process of developing system capabilities has not been well investigated, but the subject relates to studies on supplier development. Quayle (2000) presents an overview of this literature and has summarized the requirements for a successful outcome as follows:

- a long-term commitment to developing and maintaining cooperative and close relationships

- proactivity by both customers and suppliers

- both parties integrating key functions and activities

- a clear framework for both parties to determine cost, price and profit

- a win-win philosophy

- and continuous improvement efforts in all activities. 
Building system capabilities may be seen as a result of a gradual maturity process, concerning complex demands that require a higher degree of customer integration (Carlsson, 2007, 2009; Krause and Ellram, 1997). Such a maturity process resembles the findings of Smals and Smits (2012). They refer to three phases of supplier development when involved in collaborative new product development: materials supply and build-to-print, outsourced detail engineering, and outsourced module development responding to customers’ high-level functional requirements.

The development of a SME system supplier is to a large extent customer driven, and it is management's job to identify the desired direction and the portfolio of collaborative customer relationships that support this strategic direction (Smals and Smits, 2012). Effective knowledge management requires willingness from both parties to share knowledge (Wu and Lin, 2013), and customer attitude is crucial for supplier development.

The relatively few studies underline that the supplier perspective is still inadequately covered by research, especially regarding the long term (Smals and Smits, 2012). This paper provides a contribution to filling this important research gap.

\subsection{Research question and limitations}

The purpose of this paper and the literature overview lead us to the research question:

How may KI with customers contribute to the transition from component supplier to system supplier?

We will limit the study to SME contract manufacturers without their own products and focus on process development as being one core system capability. Process development is usually understood to cover many areas, such as quality, cost, volume and mix flexibility, lead time, delivery precision and continuous improvements. 


\section{Method}

\subsection{A longitudinal single case study}

Identifying KI processes requires deep insight into and knowledge of a complex phenomenon over time. This motivated us to choose a single case study (Yin, 1994) combined with a longitudinal approach inspired by Van de Ven and Huber (1990). The longitudinal approach is a key aspect of this study that helps in shedding light on the KI processes at play when a SME develops system supplier capabilities, processes that would not be possible to uncover in a single-point study. The unit of analysis is the process of KI when developing supplier capabilities in a SME. The choice of the case company was governed by the fact that the studied supplier is in the middle of a transition towards system supplier capability. In addition, the main author has been employed and a member of the executive group in this company for more than 15 years, with one of the main duties being business development. This facilitated access to relevant data of all kinds.

\subsection{Research design}

Both basic requirements and some areas of special interest in achieving system supplier capability have earlier been identified (Carlsson, 2009). In order to drill deeper and focus on the concept of system supply and how KI enables the development of system capabilities in a small supplier, the current study is based on fourteen semi-structured in-depth interviews with chief executives of the studied supplier (CEO, sales manager, quality manager and purchasing manager) and of its customers (see Table 1).

The initial interviews and discussions with managers at the focal company explored the 
consistency of perceptions about system supplier capability, with regard to customer demands and required development steps, and management of resources and capabilities. The findings were validated by presenting them to the eight members of the management group and subjecting them to a thorough discussion at a special seminar. Interviews with customers of the focal supplier aimed at clarifying how customers value and work with their prioritized suppliers, with issues such as "which are the most focused capabilities" and "how are you working with supplier development". The questions also related to trends in supplier development and if the customers had changed their way of working with different suppliers. In order to examine the required capabilities over time, the authors studied how differences in demand have been handled in a number of its customer business cases. The researchers studied relevant internal documentation and customer agreements. These issues are also part of the business development work and have been frequently discussed by management, as well as with the market group and the purchasing group. An in-depth interview with the responsible key account manager (KAM) of the focal supplier confirmed the impression we had of different types of collaboration developing depending on the duration of the customer relationship and/or the kind of capabilities required by the customer.

The rare access to thorough data about the case supplier motivated the single case approach, even though this affects validity and generalization. The part of the research that is built on interviews relies on the ability of the respondents to see, describe and explain their reality. The one author's many years of experience with business development issues from working at management level have likely provided good insights into the questions we investigated from the company's point of view. The main author knows well many of the respondents' professional capacities, which also facilitated interpretations and follow-up discussions and interviews for issues that 
needed clarifying. However, the research covers a developing area and the people involved are facing ever-changing demands, which would make it difficult to replicate this research with similar conclusions.

\section{Case study}

\subsection{The case company}

The supplier in this case study is a SME supplier within mechanical manufacturing (a contract manufacturer with no products of its own). With four production units, in total about 200 employees, the supplier is aiming at developing system supplier capabilities. The history shows some different priorities over time.

The company started out in 1976 as a small component supplier. Steady growth enabled investments in further machine capacity and production competences, continuously expanding the production capabilities within machining and sheet metal.

From the mid 1990s the focus on systematic quality work and administration grew. Customer demands for quality management systems increased, and the first ISO 9002 certification was conducted in 1995. In the middle of the 1990s assembly of components to modules was offered to a large international customer and a long-term collaboration was established. Increased use of IT solutions for electronic order communication (EDI) followed in collaboration with large customers. The supplier grew into a small company group over time. A central administrative unit with resources for development of quality systems, IT and management to support customer collaboration was established.

From the early 2000s the supplier aimed to work more closely with customers. The structured quality and environmental work with third-party certifications continued. Increasing global competition led to further steps by the supplier to get closer to the 
customers and their product development processes: after initially only prototyping, the supplier started taking a more active part in the customers' new product development projects. A few mechanical systems of a more complete nature were co-developed together with customers and then manufactured.

The decline during the financial crisis of 2008-9 was to the impetus for introducing Lean production, investing considerable working time in training and implementation of a Lean manufacturing system. The introduction of continuous improvements groups, new structures for daily management meetings, and the use of other Lean tools were applauded by most of the personnel as well as most of the customers. Clarification and standardisation of different processes became a focused goal, to improve the stability of quality performance and delivery precision.

From 2010 cost pressure forced a focus on profitability and increased collaboration in more complex customer projects. Sales dropped in the uncertain global economic environment, while increasing price competition necessitated cuts in the workforce. This also meant setbacks in the diversified administration necessary for the management of different tasks as system supplier. The supplier's expressed intention, however, is to continue to grow, maintaining the role of trusted long-term partner and expanding the system supply offering to a number of large customers.

\subsection{Improving process development through three types of integration with customers}

Improving the process development capability has been a clear focus of the case SME supplier (hereafter called the Supplier) for several years, due to customer requirements for better quality and lower cost through continuous improvements.

The Supplier has established a structured process to get back on track after performance problems (e.g. delayed deliveries or quality defects). But upon starting its 
role as system supplier, the firm also encountered a need to develop capabilities to meet more specific demands, such as developing customer-specific tools to improve the production process or taking part in cost reduction initiatives. The Supplier's customers also emphasise systematic work on process improvements in order to secure long-term competitive price levels. These improvements might be aligned to the customer segments or industries (e.g. industry-specific quality certifications) but also need to be of a more general nature, including supporting qualified production technology and introducing efficient logistic solutions. As one customer commented: 'A system supplier must ensure the entirety of its (sub-)systems and be able to affect its quality and its production-friendliness'.

Some of these subsystems are managed by the Supplier largely on its own, while some areas are more dependent on customer collaboration. This collaboration with customers can be classified in three types depending on both trust and customer commitment (summarized in Table 2 below).

The first type appears quite early in a customer relationship and concerns directives from the customer about necessary measures to master a problem, perhaps concerning quality or delivery precision. One customer criterion for choosing a new supplier is third-party quality certification. In addition to quality and delivery reliability, flexibility and communication are important basic capabilities. From the supplier's point of view, increased flexibility is achieved through process development. Another type of collaboration normally occurs when the parties know each other better and concerns advisory supplier/customer collaboration to achieve enhancements, such as supplier suggestions for improvement on a product drawing that will simplify manufacturing. Regarding what additional capabilities the customers demand from system suppliers, technology development and doing their own design are emphasised. A third type of 
customer integration presupposes deep customer commitment and concerns specific projects requiring cross-functional competence of both parties (mostly about new product development or collaborating on possibilities for rationalisation or cost reduction projects). In addition to in-depth knowledge about the customer and the customer's prerequisites, purchasing is another emphasised capability. This requires a broad purchasing organisation that takes responsibility for and utilizes the skills of its subcontractors to increase customer value. Next these different types of collaboration are further described.

\subsubsection{Development of stable processes driven by external audits and standardisation}

The first type of customer collaboration (though limited) involves straight directives, with very little collaboration and very little knowledge exchange.

The capability building of the Supplier is often driven by external quality audits. This means that representatives from the customer's purchasing and quality departments analyse and assess the different business processes, and the Supplier gets clear improvement instructions. Besides the assessment of the processes, the Supplier also learns from best practices in different areas. The customer that seeks a long-term supplier relationship often offers support and assistance, which in turn opens opportunities for knowledge transfer and strengthening supplier/customer relations. These supplier assessments also represent a chance for the Supplier to learn about assessment of its own suppliers.

One customer requirement for choosing a new supplier is a third-party quality certification. In addition to quality and delivery reliability, flexibility and communication are important basic capabilities. From the supplier's point of view, increased flexibility is achieved through process development. 
Standardisation is a key capability during this type of collaboration. Two typical examples of statements from the interviewed managers are: 'Stable processes provide more power and space, a prerequisite for gaining flexibility' and 'Standardised processes result in less “firefighting” and result in a more even workload.'

Supplier capabilities such as continuous improvements (e.g. through the implementation of quality management systems or Lean Production) are developed by the Supplier on its own in order to ensure quality and improve efficiency and effectiveness in the business. Some certificates such as ISO 9001 have become a standard requirement for all types of suppliers. But the ever-increasing requirements on system suppliers to achieve different standards and different certificates covering different lines of business (e.g. specific quality standards for the car industry, medical technology or rail technology; specific environmental standards and codes of conduct; or specific safety standards concerning information handling or explosives risks) pose a strategic challenge for a SME supplier such as the Supplier. Implementing a new certification or regulation standard means investing time and other scarce resources to integrate and consolidate new routines that must yield stable business processes and long-term customer relationships, as well as enhancing the possibility of attracting other customers.

\subsubsection{Advisory supplier and customer collaboration as the basis for mutual} process improvement

This second type of customer collaboration often involves suggestions from either the Supplier or the customer. It might lead to exchange of knowledge if the other party finds the advice good and chooses to follow it. This might also signal interest from both parties for extended collaboration and create conditions for KI. The KAM predicts: 'As future winners, we have staff at our customers' sites and customers in our company, 
eliminating boundaries between companies through cross-functional and interorganisational work'.

Typically, customers with a supplier development programme plan regular meetings (often three to four times per year) with their strategic suppliers. The customer presents their expected development and critical competitive factors, and they discuss the possibilities for the Supplier to meet those demands. Both parties have an opportunity to discuss process improvements in the collaboration. Specific action programmes for the Supplier or collaborative projects with the customer might be suggested, possibly leading to customised solutions to develop or change parts of the business in order to shorten lead times and thus increase the competitiveness of both the customer and the supplier itself. For example, negotiations preceding a vendor-managed inventory (VMI) arrangement increase both the supplier's and the customer's understanding of issues influencing effective inventory management. A customer demand for a specific VMI tool to increase visibility and integration with the customer ERP system might be a valuable driver for the Supplier. Once set up, this provides a supplier capability that can be implemented in other settings, influencing both flexibility and costs. Customer-specific routines must be explicit and require extra focus on documentation and standardisation, since much of the initial learning otherwise might get lost over time through forgetting and personnel turnover.

Knowledge about the sourcing and supplier management processes is emphasised as the customers assign to the Supplier the responsibility for managing the purchasing and the supplier base. More structured and interactive work is required to integrate the knowledge of cross-functional specialists (e.g. sales, quality and production functions). 
The Supplier is also expected to make planned audits of its strategic suppliers, including checking for a code of conduct and evaluating its ecological footprint. In order to get stable processes and lower costs, some customers initially help out in this process, thus transferring their knowledge of the procedure of supplier assessment. In return, the Supplier may be able to contribute valuable technical production knowledge in this sourcing process.

As the Supplier has acquired more responsibilities for sourcing, planning, production, stockholding etc., it has also participated in cost-cutting projects with the customer. Integrating supplier and buyer knowledge in such projects often results in changes in routines and/or product changes, leading to a more cost-efficient process.

\subsubsection{Integration of knowledge on process and product development}

The third type of customer collaboration take place during projects to streamline production or develop products. One customer summarized the intentions well: 'In product development you want to combine the supplier's knowledge about production techniques and design with the customer's knowledge about the function'.

The Supplier regards participating in the customer's new product development projects as the most rewarding from a KI perspective. A comment from one customer defines the challenges: 'A system supplier should "understand" the complete product and provide suggestions for improvement to optimise the end result as regards function, cost, lead time, etc'. Ideally the customer obtains a deeper understanding of the supplier's planning and production processes and how these are affected by contractual conditions (e.g. the size of delivery batches, or forecast uncertainty), while the supplier gets more input about customer-specific context or industry factors such as competitive cost levels for manufacturing and materials. The Supplier, with expertise in production planning and specific production processes, contributes facts and ideas for 
improvements, such as changes to materials or other changes for more cost-efficient production. A deeper knowledge of the customer's competitive situation also allows for improvement work on logistics solutions, among others.

These different types of customer collaboration representing three levels of knowledge integration are summarized as follows, with examples of topics of the respective type (Table 2).

\subsection{Challenges for the Supplier}

Managing the increasing number of different types of suppliers has proven to be a special challenge. The administrative resources are scarce, limiting the possibilities for purchasers to specialise, whether on different materials, different types of suppliers, or different areas of sourcing. The customers' demands for working with supplier development, contingency planning, code of conduct and more are difficult to comply with, as neither time nor skill is sufficient.

Another challenge concerns the comparatively few employees of the Supplier; many are employed in more than one function and much knowledge is embodied in individual persons. For sustainable capabilities the management needs to identify such core competences and key resources and embed this knowledge in organisational routines and standardised procedures.

\section{Discussion}

The current study has been guided by the question of how knowledge sharing and KI in collaboration with customers can contribute to the SME supplier transition to system supplier. The three types of customer collaboration described above may be seen as different levels. Moving between these levels require specific capabilities. We have 
identified three such capabilities associated with the different levels of KI with customers.

\subsection{Level 1: Customer directives require a capability to manage standardised and efficient processes}

The supplier's organisational processes to maintain and strengthen the suppliercustomer relationship make an important stepping stone for KI with customers. This level mainly involves knowledge transfer. This study provided examples of customers offering guidance and support to help the supplier develop desired capabilities (Nath et al., 2005), partly in accordance with Quayle’s (2000) reported requirements for a successful supplier development outcome. Personal commitment is then a very important strength of the SME system supplier: the customer is large enough to be important and well-known within the supplier organisation, yet must not be so big that the supplier stands and falls with the customer. Relationship management and building trust (Rosell et al., 2014), are key ingredients for the system supplier to align capabilities with changing demands from the selected customers - enabling the close cooperation that promotes KI in the supply chain.

A prerequisite for this is the internal capability to standardise and integrate routines to different well-functioning processes that ensure the fulfilment of basic requirements (quality, delivery performance and flexibility, cost). The case study provides several examples of activities that appear in different situations, a variety that has also been suggested by Johansson et al. (2011). Among these, some are mainly internal, and of two different kinds: (a) regular improvement work with plans, rules and standardised information for the supplier's process development, often involving capabilities for satisfactory basic requirements, and (b) intense cross-functional problem-solving activities ('firefighting'), often following directives from an important 
customer in order to identify problems and present a viable and lasting solution. The 'firefighting' activities are examples of organisational routines that lead to more dialogue among different functional specialists, both internal and external, and may

result in new learning and the renewal of working methods and processes. The boundaries between standard procedures and processes supporting organisational flexibility have, however, proven difficult for the Supplier to manage.

The case study illustrates how the assessment processes can constitute a step in the development of system supplier capabilities and a means to increase competitiveness. The value of learning from experienced auditors of many large customers has also been emphasised (e.g. Hancké, 1998; Inemek and Tuna, 2009). The experiences and lessons learned from these processes have provided the necessary assistance for the Supplier to create its own supplier assessment policies and tools and deploy them. Another important learning effect from the customers' assessments is an outside view of the business. A lack of competence in an important business process might be a hint of a major obstacle and provide suggestions for improvement that would work with other customers with similar needs (Barclay, 2005). A well-conducted assessment process increases the understanding of the reasoning of both parties, not only about customer requirements and supplier performance standards but also about the attitudes of the respective parties towards issues like collaboration, improvement work, and long-term development.

\subsection{Level 2: Collaboration requires management capabilities}

Management's approach and ability to form close collaborations with customers that emphasise long-term orientation is crucial. Management processes and focus seem to be of great significance to coordinate internal and external work. Important areas to form KI capability are the strategic capabilities, organisational structures, KI systems and 
procedures, and the people involved (Berggren et al., 2011; Mandal, 2015; Zekić et al., 2016). This might prove challenging if the management of the SME supplier lacks adequate competence and resources to interact with large customers and adopt an overall perspective on the supply chain.

Customers that are working actively with their supplier development programmes create a framework for collaboration with the Supplier. They see the relationship as a partnership, expect the Supplier to contribute design and production technology expertise, and they take a demanding but supportive approach to help the Supplier develop. The customer's role is thus crucial. A careful selection of customers to work up who are positive to collaboration, combined with the selection and development of strategic suppliers, is a way to increase value for both the system supplier and the customers (Smals and Smits, 2012).

Increased knowledge exchange with customers often concerns specific improvements to the customer product or the supplier-customer collaboration. Such improvement initiatives may originate from regular and planned supplier-customer meetings or from discussions concerning new product development, both leading to cross-functional collaboration to different degrees and on different levels over the organisational borders.

To get the full value of investments in extended customer partnerships, the management of the SME system supplier must have a clear vision of what capabilities to sustain. As many industries are global and competition is rapidly changing, it is of vital importance, though challenging, for a SME manufacturer to monitor the outside world, keeping track of trends in the industry and transfers of ownership of their current customers in order to quickly adapt to new conditions. Maintaining close relations at 
different organisational levels in various inter-organisational processes with customers and suppliers yields valuable information in this respect.

The customer's ambition to reduce the number of suppliers is combined with regularly planned meetings with their strategic suppliers, which are often also system suppliers. This coincides well with the Supplier's wish for frequent cross-organisational and cross-functional meetings as a forum for communication about product changes, forecasts, production facilities, logistic solutions and more. Such meetings may lead to new projects and thus more integrated business relations. Customers expect a system supplier to gain experience from doing business with several other demanding customers from different industries, so this learning by the Supplier is important from a KI perspective. Allowing people with similar knowledge who 'speak the same language' from both organisations to meet facilitates trust and is further regarded as important for KI, which is in line with the findings of Rosell et al. (2014). The idea is for representatives from both organisations to get to know each other in order to remove bottlenecks and establish an exchange of experience that creates stability and long-term efficiency.

The study indicates that one SME management capability involves seeking out organisations (customers and strategically important suppliers) where long-term relationships may be developed and avoiding organisations that repeatedly act only to maximize profit. This is also the stated goal but not always seen in practice. The problem here might be part insufficient strategic management capability and part the many event-driven transactions from a need to 'fill the workshop', which sometimes has made consolidation of the customer base and the business more difficult. 


\subsection{Level 3: Capability of collaborating in new product development projects}

The case clearly illustrates how essential the collaboration and development processes with rather few long-term customers are for the SME supplier in the transition to system capabilities. Especially important for KI with customers is the supplier's participation in new product development processes, requiring detailed knowledge about the customer's products, their functionality and market conditions. The supplier manufacturing expertise is required by customers who often have outsourced their own production. In return, a well-functioning product development process creates favourable conditions for the supplier's production development within a well-defined manufacturing niche or specific industry. Increasing demands, partly industry- or customer-specific, require the SME supplier aiming for system supply to focus on only a few industries while looking out for significant synergies in order to be able to align and rapidly adopt skills and resources. Certifications and industry standards are costly to implement and maintain, so the routines and processes they support must be required by a majority of the customers.

The organisational routines are to be seen both in the 'firefighting' activities and in the more planned improvement meetings or new product development projects at different levels of integration with customers. These activities lead to more dialogue among different functional specialists, both internal and external, and may result in new learning and the renewal of working methods and processes.

The case study illustrates how development capabilities grow continuously over time in a tight interaction with key customers, capabilities that such researchers as Teece et al. (1997) claim are necessary for sustainable competitiveness. A crossfunctional as well as a cross-organisational approach is needed to combine and develop technical, commercial and managerial solutions with efficient processes. Relational capabilities are crucial, since increasing product complexity requires more specific 
competences and solutions to be developed in collaboration with the customer (Croom and Watt, 2000).

\section{Conclusions}

This study analyses how knowledge integration with customers can contribute to the development of system supplier capabilities within a SME supplier. KI is understood as bringing different types of knowledge together, exchanging and combining them to generate complementary knowledge: social interactions in cross-functional and crossorganisational groups, supported by relevant organisational procedures.

Based on a deep longitudinal case study, two conclusions can be drawn. One conclusion and a major contribution is that integration of knowledge with customers seems to be an effective means to build system supplier capabilities within a SME manufacturer. The analysis also illustrates that this capability building is a sequential process that relies on the stepwise integration of knowledge with different customers. In the case company, the Supplier, three levels of KI were identified, ranging from unidirectional knowledge transfer to mutual knowledge exchange to full-range knowledge integration (see Table 3). The character of the KI process differs at each level due to the degree of responsibility and the content of the collaboration with the customers. The developmental stages of the Supplier represent a progression from mostly internal KI processes, such as the implementation of quality management systems, to an increasing degree of inter-organisational and collaborative KI processes with customers.

A second conclusion and a theoretical implication is that each level of KI requires specific capabilities of the supplier. This implies that the development of system supplier capabilities through KI with customers necessitates a process of 
developing certain capabilities. On the first level, the capabilities are characterised by unidirectional knowledge transfer; the capability of providing stable processes and performance (e.g. quality, delivery and cost) is crucial. The mutual knowledge exchange processes at level 2, such as those concerning cost reduction projects, require the capabilities of managing not only internal but also external relationships. This includes a capability of strategically selecting customers that are interested in long-term relationships. At the third level of KI, the capability of developing products and related processes becomes necessary. It is important to stress that the different capabilities are cumulative. In other words, the capabilities needed on level 1 remain necessary also at levels 2 and 3. Similarly, the capabilities at level 2 are still needed at level 3.

We make two suggestions for further research. As this is a single case study, there is a need to investigate how general and applicable the results are for other SME suppliers by conducting a study on a larger scale. The line of business (production niches or different customer segments) could possibly also involve different scenarios. More research is needed to clarify the different paths of development for SME system suppliers and the various ways in which these different paths influence KI mechanisms in the supplier-customer relationship. This stepwise development and its cumulative capabilities might relate to a maturity model.

One managerial implication from this study is the importance of strategically choosing customers to work with, favoring close collaboration. System supplier capabilities are not built in isolation; customers influence the forming of supplier capabilities to a very great extent.

\section{References}

Barclay, I. (2005) 'Supply chain management in SMEs - Benchmarking best practice core competencies', Journal of General Management, Vol. 30 No. 3, pp. 35-50. 
Berggren, C., Bergek, A., Bengtsson, L., Hobday, M. and Söderlund, J. (Eds.), (2011) Knowledge Integration \& Innovation - Critical Challenges Facing International Technology-Based Firms. Oxford University Press, Oxford, UK.

Brusoni, S., Prencipe, A. and Pavitt, K. (2001) 'Knowledge specialization, organizational coupling, and the boundaries of the firm: Why do firms know more than they make?’, Administrative Science Quarterly, Vol. 46, pp. 597-621.

Cambra-Fierro, J.J. and Polo-Redondo, Y. (2008) 'Long-term orientation of the supply function in the SME context', International Small Business Journal, Vol. 26 No. 5, pp. 619-646.

Carlsson, I. (2007) 'Towards system capability: Identifying logistics and manufacturing demands for small suppliers'. Paper presented at the 14th annual EurOMA Conference, 17-20 June 2007. Ankara, Turkey.

Carlsson, I. (2009) Meeting Increased Logistical Demands, Developing as a Small- and Medium-Sized System Supplier. Linköping Studies in Science and Technology LiU-TEK-LIC-2009:23, Linköping University.

Croom, S. and Watt, A. (2000) 'Managing operations improvements through relational capabilities in the context of small-firm networks', International Journal of Logistics: Research and Applications, Vol. 3 No. 1, pp. 83-96.

Day, G.S. (1994) 'The capabilities of market-driven organizations', Journal of Marketing, Vol. 58 No. 4, pp. 37-52.

Eslami, M.H. and Lakemond, N. (2016) 'Knowledge integration with customers in collaborative product development projects', Journal of Business \& Industrial Marketing, Vol. 31 No. 7, pp. 889-900.

Gadde, L-E. and Håkansson, H. (2001) Supply Network Strategies. John Wiley \& Sons, Chichester, UK.

Gadde, L-E. and Snehota, I. (2000) 'Making the most of supplier relationships', Industrial Marketing Management, Vol. 29, pp. 305-316.

Grant, R.M. (1991) 'The resource-based theory of competitive advantage: Implications for strategy formulation', California Management Review, Spring, pp. 114-135.

Grant, R.M. (1996a) 'Toward a knowledge-based theory of the firm', Strategic Management Journal, Vol. 17 (Winter), pp. 109-122.

Grant, R.M. (1996b) 'Prospering in dynamically-competitive environments: Organizational capability as knowledge integration', Organization Science, Vol. 7 No. 4, pp. 375-387. 
Hancké, B. (1998) 'Trust or hierarchy? Changing relationships between large and small firms in France', Small Business Economics, Vol. 11, pp. 237-252.

Handfield, R.B., Ragatz, G.L., Petersen, K.J. and Monczka, R.M. (1999) 'Involving suppliers in new product development', California Management Review, Vol. 42 No. 1, pp. 59-82.

Heide, M., Vaaland, T.I. and Gronhaug, K. (2008) 'The paradoxical role of competence development in supply chain management: Empirical findings from Norway', International Journal of Logistics: Research and Applications, Vol. 11 No. 1, pp. 1-15.

Helander, A. and Möller, K. (2008) 'System supplier's roles from equipment supplier to performance provider', Journal of Business \& Industrial Marketing, Vol. 23 No. 8, pp.577-585.

Henrekson, M. and Stenkula, M. (2006) Företagsstruktur och nyföretagande i Sverige Expertrapport till kris- och framtidskommissionen [Company structure and new entrepreneurs in Sweden: Expert report to the Crisis and Future Commission], Svenskt Näringsliv. Stockholm: Institutet för Näringslivsforskning.

Hillebrand, B. and Biemans, W.G. (2004) 'Links between internal and external cooperation in product development: An exploratory study', Journal of Product Innovation Management, Vol. 21, pp. 110-122.

Hilmola, O-P., Lorentz, H., Hilletofth, P. and Malmsten, J. (2015) 'Manufacturing strategy in SMEs and its performance implications', Industrial Management \& Data Systems, Vol. 115 No. 6, pp. 1004-1021.

Huin, S.F., Luong, L.H.S. and Abhary, K. (2002) 'Internal supply chain planning determinants in small and medium-sized manufacturers', International Journal of Physical Distribution \& Logistics Management, Vol. 32 No. 9, pp. 771-782.

Inemek, A. and Tuna, O. (2009) 'Global supplier selection strategies and implications for supplier performance: Turkish suppliers’ perception', International Journal of Logistics: Research and Applications, Vol. 12 No. 5, pp. 381-406.

Johansson, M., Axelsson, M., Enberg, C. and Tell, F. (2011) 'knowledge integration in inter-firm R\&D collaboration: How do firms manage problems of coordination and cooperation?' in Berggren, C. et al. (Eds.), Knowledge Integration \& Innovation - Critical Challenges Facing International Technology-Based Firms, Oxford University Press, Oxford, pp.148-169. 
Kannan, V.R. and Tan, K.C. (2003) 'Attitudes of US and European managers to supplier selection and assessment and implications for business performance', Benchmarking: An International Journal, Vol. 10 No. 5, pp. 472-489.

Kim, K.I., Syamill, A. and Bhatt, B.J. (2007) 'A resource-based theory of supplier strategy', International Journal of Logistics Systems and Management, Vol. 3, No. 1, pp.20-33.

Koufteros, X.A., Rawski, G.E. and Rupak, R. (2010) 'Organizational integration for product development: The effects on glitches, on-time execution of engineering change orders, and market success', Decision Sciences, Vol. 41 No. 1, pp. 4980.

Krause, D.R. and Ellram, L.M. (1997) 'Critical elements of supplier development: The buying-firm perspective', European Journal of Purchasing \& Supply Management, Vol. 3 No. 1, pp. 21-31.

Maloni, M.J. and Benton, W.C. (1997) 'Supply chain partnerships: Opportunities for operations research', European Journal of Operational Research, Vol. 101, pp. 419-429.

Mandal, S. (2015) 'An empirical-collaborative model of supply chain agility', International Journal of Logistics Systems and Management, Vol. 21 No.4, pp. 465-502.

Morrissey, W.J. and Pittaway, L. (2006) 'Buyer-supplier relationships in small firms: The use of social factors to manage relationships', International Small Business Journal, Vol. 24 No. 3, pp. 272-298.

Nath, P., Sandhya, G.D. and Mrinalini, N. (2005) 'Supply chain as knowledge management', International Journal of Logistics Systems and Management, Vol. 1 Nos. 2/3, pp. 267-278.

Quayle, M. (2000) 'Supplier development for UK small and medium-sized enterprises', Journal of Applied Management Studies, Vol. 9 No. 1, pp. 117-133.

Rosell, D.T., Lakemond, N. and Wasti, S.N. (2014) 'Integrating knowledge with suppliers at the R\&D-manufacturing interface', Journal of Manufacturing Technology Management, Vol. 25 No. 2, pp. 240-257.

Smals, R.G.M. and Smits, A.A.J. (2012) 'Value for value - The dynamics of supplier value in collaborative new product development', Industrial Marketing Management, Vol. 41, pp. 156-165. 
Smith, A.D. (2012) 'Vertically integrated product/process strategies in highly competitive environments: Case study of the flexible door industry', International Journal of Logistics Systems and Management, Vol. 11 No. 1, pp. 93-113.

Smith, A.D. and Rupp, W.T. (2013) 'Supply supplier integration, procurement, and outsourcing: Case study of SCM social capital benefits’, International Journal of. Logistics Systems and Management, Vol. 14 No. 2, pp. 221-241.

Sydow, J., Schreyögg, G. and Koch, J. (2009) 'Organizational path dependence: Opening the black box', Academy of Management Review, Vol. 34 No. 4, pp. 689-709.

Tang, C.S. (2007) 'Supplier relationship map’, International Journal of Logistics: Research and Applications, Vol. 2 No. 1, pp. 39-56.

Teece, D.J., Pisano, G. and Shuen, A. (1997) 'Dynamic capabilities and strategic management', Strategic Management Journal, Vol. 18 No. 7, pp. 509-533.

Tell, F., Berggren, C., Brusoni, S. and van de Ven, A. (Eds.) (2017). Managing Knowledge Integration across Boundaries, Oxford University Press, Oxford, UK.

van de Ven, A.H. and Huber, G.P. (1990) 'Longitudinal field research methods for studying processes of organizational change', Organization Science, Vol. 1 No. 3, pp. 213-219.

Wu, L-W. and Lin, J-R. (2013) 'Knowledge sharing and knowledge effectiveness: learning orientation and co-production in the contingency model of tacit knowledge', Journal of Business \& Industrial Marketing, Vol. 28 No. 8, pp. 672-686.

Yang, J. (2013) 'Harnessing value in knowledge management for performance in buyersupplier collaboration', International Journal of Production Research, Vol. 51 No. 7, pp. 1984-1991.

Yazici, H.J. (2013) 'Supplier perceptions of knowledge sharing in buyer-supplier relationships: A service example', International Journal of Logistics Systems and Management, Vol. 16 No. 3, pp. 315-339.

Yin, R.K. (1994) Case Study Research. Sage Publications, Thousand Oaks, CA.

Zekić, Z., Rupčić, N. and Jakopič, M. (2016) 'Learning platform for supply chain optimisation', International Journal of Logistics Systems and Management, Vol. 23 No. 1, pp. 53-75. 
Zhang, Q., Vonderembse, M.A. and Lim, J-S. (2005) 'Logistics flexibility and its impact on customer satisfaction', The International Journal of Logistics Management, Vol. 16 No. 1, pp. 71-95. 
Table 1. Data sources

\begin{tabular}{|c|c|c|c|c|c|}
\hline Year & $\begin{array}{l}\text { Number of } \\
\text { interviewees }\end{array}$ & $\begin{array}{l}\text { Role } \\
\text { interviewee }\end{array}$ & Company & $\begin{array}{l}\text { Interview } \\
\text { model and } \\
\text { duration }\end{array}$ & $\begin{array}{l}\text { Purpose to clarify } \\
\text { system supplier role. } \\
\text { Issues covered: }\end{array}$ \\
\hline $\begin{array}{l}1998- \\
2015\end{array}$ & \multicolumn{2}{|c|}{$\begin{array}{l}\text { Role of the researcher: } \\
\text { Business developer }\end{array}$} & $\begin{array}{l}\text { Focal company: } \\
\text { the Supplier }\end{array}$ & \multicolumn{2}{|c|}{$\begin{array}{l}\text { Participating in operative and strategic } \\
\text { meetings in the Purchase group, } \\
\text { Management group and at Board meetings. }\end{array}$} \\
\hline 2008 & 1 & Quality manager & The Supplier & $\begin{array}{l}\text { In-depth } \\
\text { interview, face } \\
\text { to face, } 3 \text { hours }\end{array}$ & $\begin{array}{l}\text { Demands, resources, } \\
\text { development steps, } \\
\text { managing capabilities }\end{array}$ \\
\hline 2008 & 1 & Purchasing mgr & The Supplier & $\begin{array}{l}\text { In-depth } \\
\text { interview, face } \\
\text { to face, } 1.5 \\
\text { hours } \\
\end{array}$ & $\begin{array}{l}\text { Demands, resources, } \\
\text { development steps, } \\
\text { managing capabilities } \\
\end{array}$ \\
\hline 2008 & 3 & $\begin{array}{l}\text { CEO, sales mgr, } \\
\text { KAM (Key } \\
\text { Account Manager) }\end{array}$ & The Supplier & $\begin{array}{l}\text { Group } \\
\text { discussion, } 4 \\
\text { hours }\end{array}$ & $\begin{array}{l}\text { Demands, resources, } \\
\text { system supplier } \\
\text { capabilities, development } \\
\text { strategy }\end{array}$ \\
\hline 2012 & 7 & $\begin{array}{l}\text { Purchasing mgrs or } \\
\text { quality mgrs }\end{array}$ & $\begin{array}{l}7 \text { different } \\
\text { customers to the } \\
\text { focal supplier }\end{array}$ & $\begin{array}{l}\text { Telephone } \\
\text { interviews, 30- } \\
45 \text { minutes }\end{array}$ & $\begin{array}{l}\text { Supplier types and } \\
\text { characteristics, supplier } \\
\text { capabilities, supplier } \\
\text { development }\end{array}$ \\
\hline 2012 & 1 & KAM & The Supplier & $\begin{array}{l}\text { Face to face, } 30 \\
\text { minutes }\end{array}$ & $\begin{array}{l}\text { How customers perceive: } \\
\text { supplier types and } \\
\text { characteristics, supplier } \\
\text { capabilities, supplier } \\
\text { development }\end{array}$ \\
\hline 2015 & 1 & KAM & The Supplier & $\begin{array}{l}\text { Face to face, } 2 \\
\text { hours }\end{array}$ & $\begin{array}{l}\text { Customer demands and } \\
\text { supplier capabilities, } \\
\text { customer relations } \\
\text { development over time }\end{array}$ \\
\hline
\end{tabular}


Table 2. Types and examples of customer collaboration

\begin{tabular}{|c|c|c|}
\hline Type 1 & Type 2 & Type 3 \\
\hline $\begin{array}{l}\text { Unidirectional knowledge } \\
\text { transfer based on } \\
\text { customer directives }\end{array}$ & $\begin{array}{l}\text { Mutual knowledge } \\
\text { exchange and } \\
\text { collaboration on process } \\
\text { improvement }\end{array}$ & $\begin{array}{l}\text { Knowledge integration in } \\
\text { development projects }\end{array}$ \\
\hline \multicolumn{3}{|l|}{ Examples } \\
\hline $\begin{array}{l}\text { Learning from quality } \\
\text { audits }\end{array}$ & $\begin{array}{l}\text { Mutual exchange of order } \\
\text { data and inventory status }\end{array}$ & $\begin{array}{l}\text { Open dialogue and open } \\
\text { calculations for mutual } \\
\text { understanding }\end{array}$ \\
\hline Assessment of processes & $\begin{array}{l}\text { Evaluating different SC } \\
\text { solutions (e.g. VMI) } \\
\text { together }\end{array}$ & $\begin{array}{l}\text { Identifying and } \\
\text { integrating } \\
\text { complementary } \\
\text { knowledge }\end{array}$ \\
\hline \multirow[t]{3}{*}{$\begin{array}{l}\text { Clarifying performance } \\
\text { criteria }\end{array}$} & $\begin{array}{l}\text { Joint activities for cost } \\
\text { cutting or reduced lead } \\
\text { times }\end{array}$ & $\begin{array}{l}\text { Securing cross-functional } \\
\text { and inter-organisational } \\
\text { collaboration }\end{array}$ \\
\hline & $\begin{array}{l}\text { Knowledge exchange on } \\
\text { sourcing and managing } \\
\text { suppliers upstream }\end{array}$ & $\begin{array}{l}\text { Running improvement } \\
\text { projects to streamline } \\
\text { production }\end{array}$ \\
\hline & $\begin{array}{l}\text { Knowledge exchange on } \\
\text { technical production and } \\
\text { materials }\end{array}$ & $\begin{array}{l}\text { Collaborating in new } \\
\text { product development } \\
\text { projects }\end{array}$ \\
\hline
\end{tabular}


Table 3. Three levels of KI and the capabilities needed

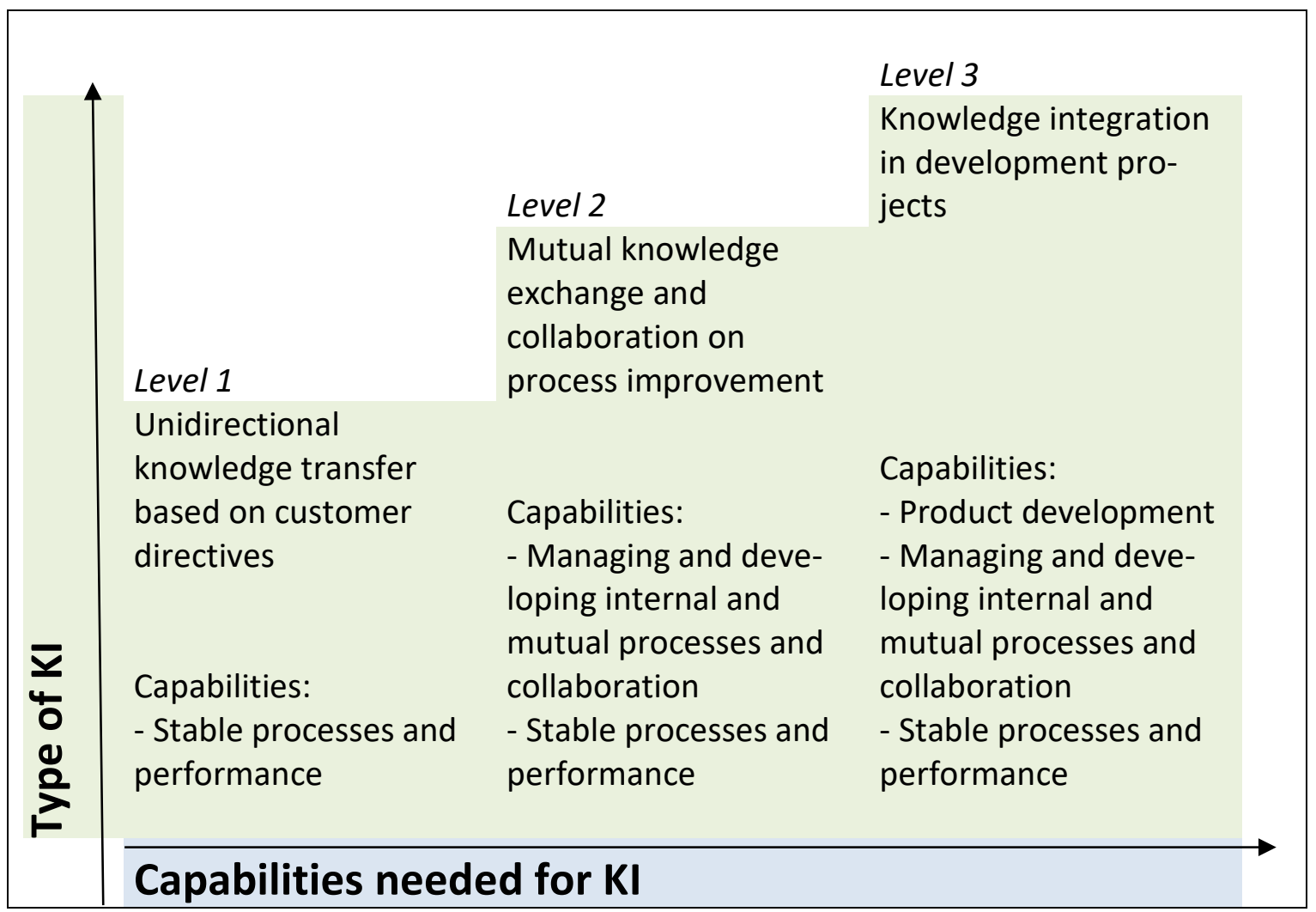

